\title{
Anthropogenic and Natural Constituents in PM1O at Urban and Rural Sites in North-Western Europe: Concentrations, Chemical Composition and Sources
}

E.P. Weijers (ECN)

M. Schaap (TNO) 


\title{
Anthropogenic and Natural Constituents $\quad 1$ in PM10 at Urban and Rural Sites in North- 2 Western Europe: Concentrations, Chemical 3 Composition and Sources $\quad 4$
}

\author{
Ernie Weijers and Martijn Schaap
}

\begin{abstract}
This study focuses on north-western region of Europe discussing 6 questions like the following: Which anthropogenic and natural constituents build 7 up the particulate matter? To what extent do they contribute to the total mass? And 8 where do these constituents originate? To answer, we elaborated data sets 9 containing chemical information of PM recently becoming available in the 10 Netherlands, Germany and Belgium.

The chemical composition of PM10 shows a considerable conformity in these 12 countries. Always, secondary inorganic aerosols (SIA) are the major constituent 13 $( \pm 40 \%)$ followed by the carbonaceous compounds $( \pm 25 \%)$. Contributions of sea 14 salt and mineral dust vary between $10 \%$ and $15 \%$ depending on presence and 15 distance of respective sources. The unidentified mass is some $15 \%$ indicating that 16 the composition of PM10 in this region is fairly well known.

PM10 concentrations and constituents appear systematically higher at urban sites. 18 Urban increments have been measured for most chemical constituents. Nearby 19 (anthropogenic) sources and reduced dispersion in the urbanised areas are the main 20 determining factors here. The observed increment for SIA is caused by more nitrate 21 and sulphate. It is explained by depletion of chloride stabilising part of the nitrate and 22 sulphate in the coarse mode. The question then arises how to assign the coarse mode 23 nitrate (and sulphate) in the mass closure exercise as they replace the chloride. $\quad 24$

Important for the national and European air pollution policy is how much of the 25 measured particulate matter is of anthropogenic origin. A simple assessment 26 indicates that 20-25\% of PM10 is of natural origin; hence, the majority of PM10 27 in the north-western-European region is of anthropogenic origin. The uncertainty in 28 this analysis is considerable, and the result is indicative.

E. Weijers $(\bowtie)$

Energy research Centre of the Netherlands (ECN), P.O. Box 1, 1755 ZG Petten, The Netherlands e-mail:weijers@ecn.nl

M. Schaap

TNO, P.O. Box 80015,3508 TA Utrecht, The Netherlands

Hdb Env Chem, DOI 10.1007/698_2012_207, (C) Springer-Verlag Berlin Heidelberg 2012 
A chemical transport model (LOTOS-EUROS) was used to obtain a detailed source apportionment. In total, $75 \%$ of the modelled PM10 mass could be explained. The important contributions to PM10 come from agriculture, on- and off-road transport and natural sources (sea salt). Secondary contributions are derived from power generation, industrial processes and combustion as well as households. Of the modelled part, $70-80 \%$ of PM10 over the Netherlands is anthropogenic. The increase in source contribution going from low to high PM levels is proportional for most sectors, except for agriculture and transport, which become more important mainly due to the more than proportional rise in ammonium nitrate concentrations. Sea-salt concentrations decline with rising PM10. The same was found for Spain, but here, the impact of Saharan dust on PM episodes is clearly recognisable and much larger than in north-western Europe. Natural sources in Spain contribute about half of the modelled PM10 concentrations. Significant anthropogenic sources are similar to those in north-western Europe.

Keywords Anthropogenic contribution, Chemical composition, Chemical transport modelling, Natural contribution, North-western Europe, PM10, Source apportionment, Spain

\section{Contents}

1 Introduction and Scope

2 Concentrations and Chemical Composition at Urban and Rural Sites

2.1 Data Sets

2.2 Handling

2.3 Chemical Composition

2.4 The Urban Increment

3 Anthropogenic and Natural Contributions to PM

in North-Western Europe

4 Modelled Origin of Particulate Matter in the Netherlands and Spain

5 Concluding Remarks

References

\section{Introduction and Scope}

Although air quality in Europe has improved substantially over the last decades, it still poses a significant threat to human health [1]. Short- and long-term health effects have been described, but so far there is no conclusive evidence which component(s) or property can be held responsible. As a consequence, the European air quality guidelines keep a focus on particulate mass, and, next to the PM10 guideline, the Directive 2008/50/EC introduced additional objectives with respect to $\mathrm{PM}_{2.5}$. Although various abatement measures have been implemented to reduce the levels of particulate matter, many European countries still have problems adhering to the guidelines; in particular, this concerns the maximum number of exceedances of the daily limit value for PM10. The heavily populated regions in the north-west of Europe is an example where problematic "hot spots" are found in urbanised and industrialised agglomerations. 
In addition to the strength and location of local, regional and continental 71 emission sources, levels and chemical composition of ambient PM depend on 72 climatology, trajectories, rain scavenging potential, recirculation of air masses, 73 dispersive atmospheric conditions and geography (proximity to coast or arid 74 zones, topography, soil cover). These factors largely differ over Europe. Reduction 75 measures in one region may therefore not be optimal for other regions. In the design 76 of a meaningful abatement strategy, one needs therefore to take into account the 77 changing characteristics of PM, or more specifically, one should assess which 78 anthropogenic and natural constituents build up the particulate matter, to what 79 extent they contribute to the total mass and where they come from.

To answer these questions, we elaborated three PM data sets bearing chemical 81 information that recently became available in the Netherlands, Germany and 82 Belgium. In addition, a first-order quantitative estimate is given of the ratio between 83 natural and anthropogenic PM10 mass; this ratio defines the "playing field" of 84 policy-decision makers. To end, a modelling exercise is described comparing the 85 major emission sources for north-western Europe (here defined as the three 86 abovementioned countries) with those of the Iberian Peninsula.

\section{Concentrations and Chemical Composition at Urban and Rural Sites}

\subsection{Data Sets}

During the last decade, a considerable number of studies have focussed on the 91 speciation of PM in different regions of Europe (e.g. [2-7, 29]). Recently, dedicated 92 measurement campaigns were carried out in north-western Europe: "CHEMKAR" 93 (Belgium) by the Flemish Environmental Agency [8], "BOP" in the Netherlands 94 within the framework of the Netherlands Research Programme on Particulate 95 Matter [9] and in North Rhine-Westphalia IUTA (Germany). 96

The respective data sets are used here to illustrate the general chemistry of PM10 97 in north-western Europe. Always, urban and rural sites have been compared. Some 98 data features are given in Table 1. The components of interest are sulphate, nitrate, 99 ammonium, elemental carbon, organic carbon, sodium, chloride and elements.

\subsection{Handling}

Chemical analyses of PM samples usually provide a major part of the total 102 particulate mass collected on a filter. Certain tracers or combination of tracers are 103 used to estimate the contributions from specific sources like sea salt or mineral dust. 104 In order to make a sound comparison between the three sets, contributions were (re) 105 
t1.1 Table 1 Data sets

\begin{tabular}{|c|c|c|c|}
\hline t1.2 Country & Name and type of site & Mass fractions & Period \\
\hline $\begin{array}{l}\text { Belgium } \\
\text { (CHEMKAR) }\end{array}$ & $\begin{array}{r}\text { Zelzate (ub), Borgerhout (ub) } \\
\text { Houtem(rb), Aarschot (rb) }\end{array}$ & PM10 & $\begin{array}{l}\text { September 2006- } \\
\text { September 2007 }\end{array}$ \\
\hline .4 The Netherlands (BOP) & $\begin{array}{l}\text { Schiedam (ub), } \\
\text { Hellendoorn (rb) }\end{array}$ & $\begin{array}{l}\text { PM10, PM2.5, } \\
\text { PM10-2.5 }\end{array}$ & January-August 2008 \\
\hline $\begin{array}{l}\text { Germany } \\
\text { (IUTA/LANUV) }\end{array}$ & Styrum (ub), Eiffel (rb) & PM10 & $\begin{array}{l}\text { April-September } \\
2008\end{array}$ \\
\hline
\end{tabular}

t1.6 $u b$ urban background, $r b$ rural background

106 calculated using the same algorithms. The presence of secondary inorganic aerosol 107 (SIA) is calculated as the sum of NO3, SO4 and NH4 and results from direct 108 measurements. Sulphate concentrations are corrected for a small amount of sea salt. 109 Carbonaceous compounds in PM contain other elements (e.g. oxygen) 110 augmenting the organic mass. Organic matter (OM) concentrations are usually 111 calculated from organic carbon, but the conversion factor remains rather uncertain. 112 Factors vary between 1.2 and 2 and probably vary between lower values near 113 sources and higher values after processing in aged air masses. Here, a factor of 1141.4 is used which seems most common in literature. Elemental carbon (EC) can be 115 measured straightforward. In the case of sea salt (SS), there are two tracers: sodium 116 and chloride. Several algorithms are in practice; one of them calculates the SS part 117 from both $\mathrm{Na}$ and $\mathrm{Cl}$. However, in the case of chloride, reactions with $\mathrm{HNO} 3$ may 118 occur in the atmosphere as well as on the filter thereby releasing $\mathrm{HCl}$ (under the 119 formation of NaNO3). In addition, the presence of chloride may suffer from the 120 evaporation of $\mathrm{NH} 4 \mathrm{Cl}$ (from quartz filters). For these reasons, sodium is selected as 121 the sole tracer: $\mathrm{SS}=3.26^{*} \mathrm{Na}$ (the factor follows from the composition of sea 122 water).

123 Various algorithms are also in use to estimate the contribution of mineral dust 124 (MD). With MD is meant all fugitive windblown and mechanically resuspended 125 dust with a composition comparable to the earth's crust. Since chemical analyses of 126 PM samples measure elements directly, the approach here is to sum over those 127 elements known to be present in the earth's crust: $\mathrm{Al}, \mathrm{Si}, \mathrm{CO} 3, \mathrm{Ca}, \mathrm{Fe}, \mathrm{K}, \mathrm{Mn}, \mathrm{Ti}$ 128 and $\mathrm{P}$ [10]. Weights were first recalculated to correct for their oxidised form (e.g. Si 129 is usually present as $\mathrm{SiO}_{2}$ ). MD is a parameter difficult to estimate. The use of other 130 algorithms in the estimation of MD results in different values, e.g. the one 131 formulated by Denier van der Gon et al. [11]. Also, local anthropogenic sources 132 may contribute (e.g. metallurgical industry).

133 Finally, the concentrations of all constituents were summated and compared with 134 the gravimetrically measured mass to establish the unaccounted mass denoted 135 unknown. The assumption here is that the various data sets accurately describe the $136 \mathrm{PM}$ characteristics. The filtration devices employed at the sites were all equivalent to 137 the reference method. However, corresponding studies use different procedures with 138 respect to filter handling, data treatment and selection, analytical techniques, etc. In 139 addition, temporal variation, local site characteristics, artefacts like volatilisation 140 and particle-bound water as well as varying distances from major sources will affect 141 results in different ways. This will affect the absolute concentrations that have been 
measured. Putaud et al. [2] extensively describe the accuracy of the analytical 142 techniques common in Europe. While ion chromatography (SIA) performs well 143 $(<10 \%)$, an accurate determination of EC, OC and MD remains a challenge. EC 144 concentrations by various techniques differ by a factor of 4 , and OC by $30 \%$. The 145 uncertainty in the determination of mineral dust amounts can reach $100 \%$ for reasons 146 mentioned above.

Only PM10 is discussed as data on PM2.5 are much less available. In our region, 148 the average mass contribution of $\mathrm{PM}_{2.5}$ to $\mathrm{PM} 10$ is about $60-70 \%$, and the relative 149 distribution of the different chemical parts in PM2.5 usually resembles that of 150 PM10. All components are present in both the fine and coarse fraction. Whereas 151 SIA, EC and OM dominate more in the fine fraction, SS and MD contribute more to 152 the coarse mode.

\subsection{Chemical Composition}

Figure 1 shows the chemical distributions for the urban and regional background 155 sites in the three PM10 data sets selected here. Common characteristics can be 156 observed: always, the major constituent is the SIA, followed by the carbon- 157 containing components $(\mathrm{EC}+\mathrm{OM})$. Smaller, but non-negligible, contributions 158 arise from MD and SS. At least $81 \%$ of the particulate mass was explained in the 159 mass balances. The highest closure was seen at the urban background site 160 Borgerhout (87\%) which seems due to relatively a high amount of carbonaceous 161 material. Relatively, there is more SIA present at the rural sites: 42-44\% versus 162 $34-41 \%$ at urban sites. However, differences between urban and rural sites are not 163 very large stressing the role of SIA in building up background levels [31, 32]. In 164 north-western Europe, agricultural activities (like livestock and soil fertilising) 165 frequently take place yielding high emissions of ammonia in rural areas. Combined 166 with the NOx emissions from intensified traffic and SO2 emissions from industry, 167 the formation of ammonium nitrate and ammonium sulphate aerosols is favoured 168 [12].

The sum of EC and OM contributes another 20-27\% (at urban sites) and 170 $18-24 \%$ (rural) to the PM mass, with OM dominating EC at most sites. Like in 171 the case of SIA, differences between rural and urban sites appear modest which 172 is probably caused by a considerable natural (biogenic) input. A study by ten 173 Brink et al. [13] on the presence of ${ }^{14} \mathrm{C}$ in PM filter samples revealed that at least 174 $64 \%$ of the organic carbon measured at an urban Dutch site was contemporary 175 (i.e. emissions from biogenic material and biomass wood combustion). 176

A gradient for sea salt is observed as expected. Near the North Sea (Houtem 177 (rural background), Schiedam (urban background)), the marine contribution can be 178 as high as $16-18 \%$. Further inland, some $6-10 \%$ is measured. In Germany, it 179 declines to some $4 \%$. On average, the sea-salt contribution in this region is a 180 substantial $10 \%$ and is due to the dominance of transport of clean marine air from 181 the West diluting anthropogenic emissions onshore and transporting the pollution 182 further eastward over the European continent. 
Urban sites
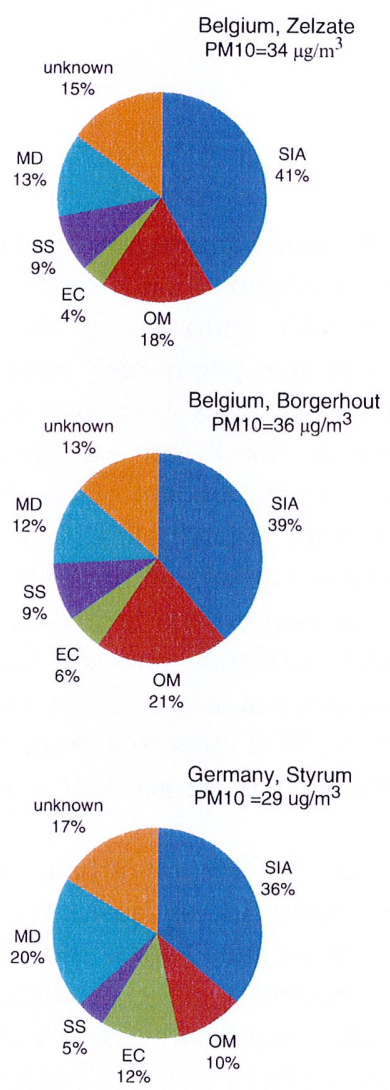

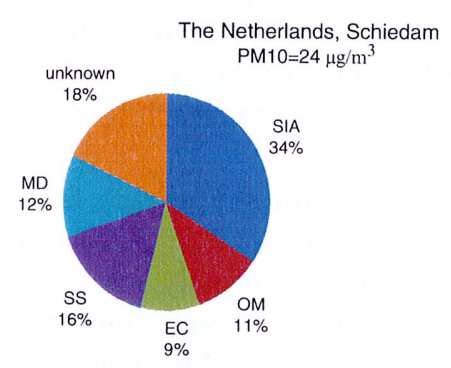

Rural sites
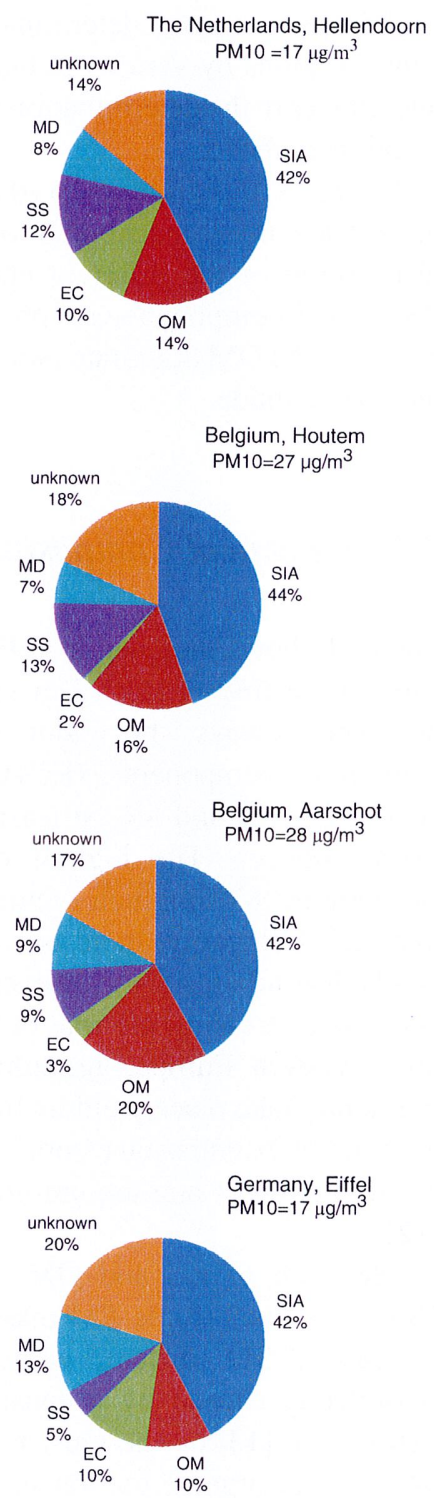

Fig. 1 Chemical distributions for the urban and regional background sites in the PM10 data sets as derived from BOP (the Netherlands), CHEMKAR (Belgium) and IUTA/LANUV (Germany)

184 The fourth constituent, mineral dust, appears comparable in Belgium and the 185 Netherlands: $12-13 \%$ at urban sites and $7-9 \%$ at rural sites. A deviant level of MD 186 is observed at the both German sites (20\% and $13 \%$, respectively) and is attributed 187 to industrial emissions (steel industry) in this region. 
Anthropogenic and Natural Constituents in PM10 at Urban and Rural Sites in...
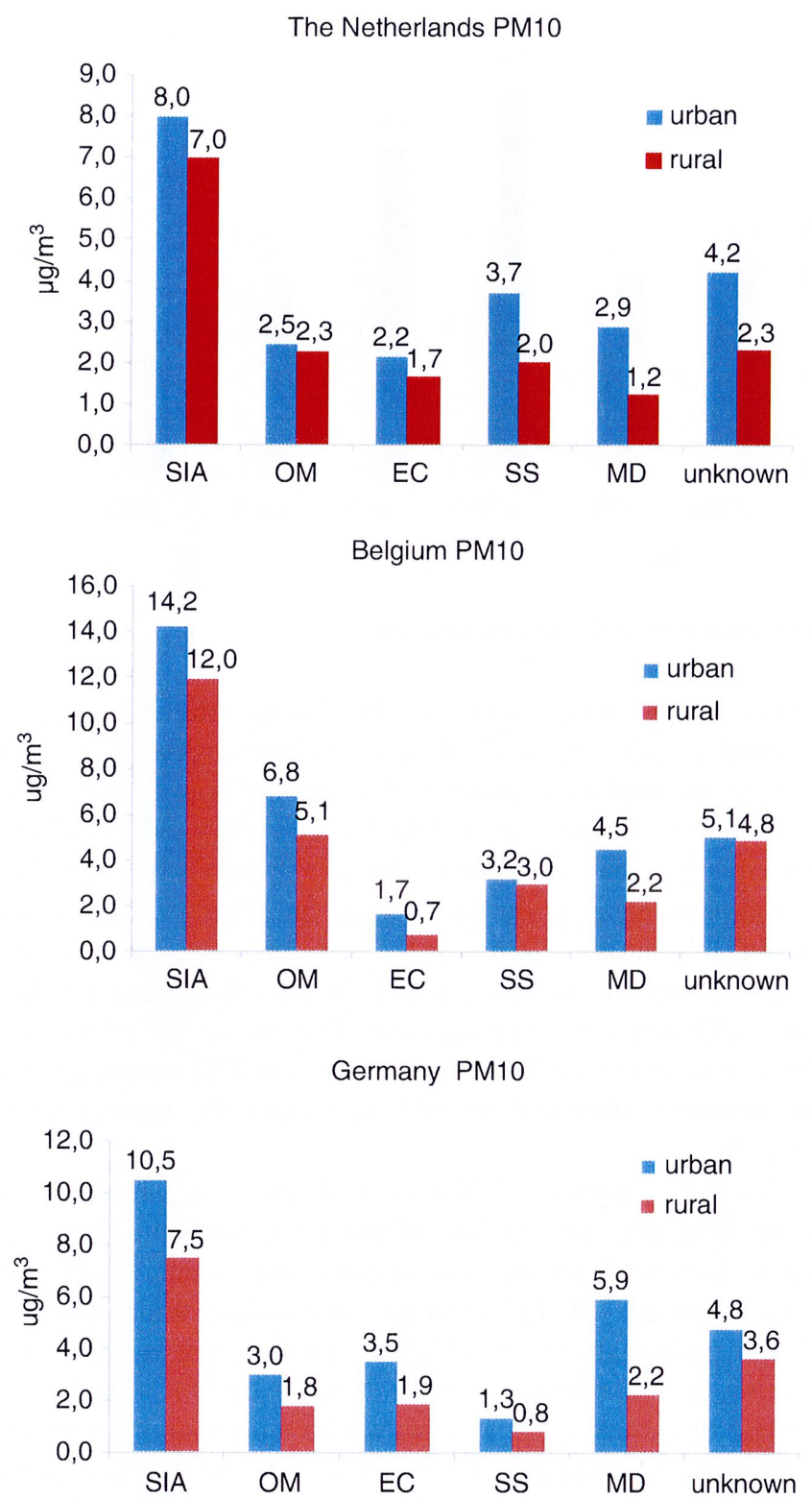

Fig. 2 Chemical distributions for the urban and regional background sites in the PM10 data sets as derived from BOP (the Netherlands), CHEMKAR (Belgium) and IUTA/LANUV (Germany)

\subsection{The Urban Increment}

In Fig. 2, the absolute concentrations at the urban and rural sites are compared. For 189 the Belgian data set, we averaged over the two urban and two rural sites. 


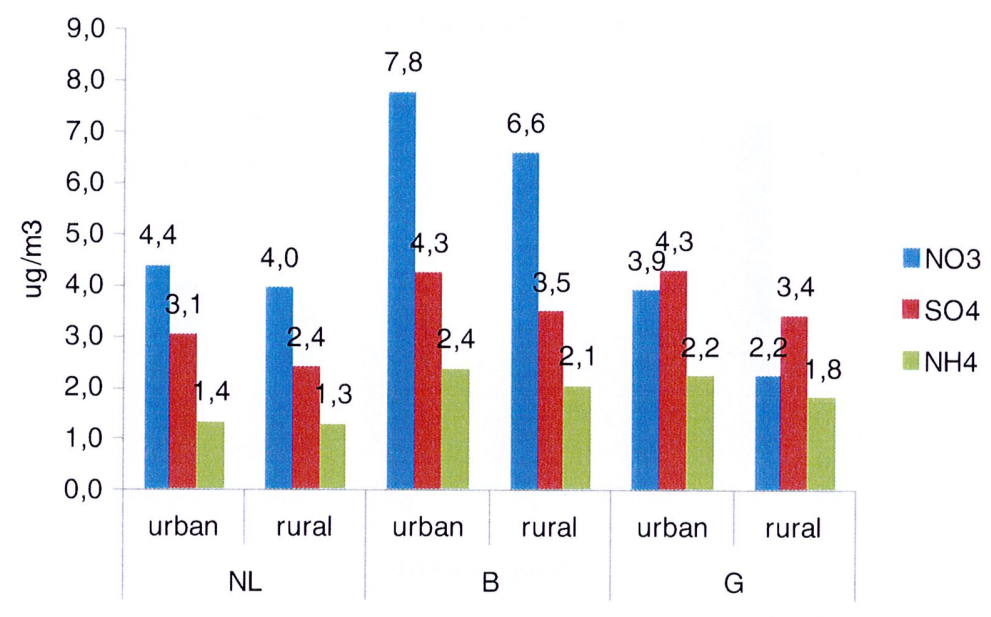

Fig. 3 The urban increment of the SIA components

191 Like in most cities in Europe, a rise in PM10 concentrations is measured when moving from rural to urban sites. Clearly, a comparison like this depends on the selection of sites, in particular distance between sites and surroundings affect results like these. Here, the increase in PM10 is between 7 and $11 \mu \mathrm{g} / \mathrm{m}^{3}$. No single constituent (or emission source) can be held solely "responsible": all (including the unknown part) appear higher at the urban sites, but there is no systematic pattern observed here. In Belgium and Germany, the increment is largely due to more SIA, $\mathrm{OM}+\mathrm{EC}$ and $\mathrm{MD}$ (between 2 and $4 \mu \mathrm{g} / \mathrm{m}^{3}$ ). In the Dutch data set, however, the unknown part contributes most. The increase of sea salt at the urban site Schiedam is due to its location close to the North Sea. The rise of MD is substantial at all sites.

The urban increment observed for SIA systematically returns for each of its 202 component (Fig. 3).

203 It is seen that the increment of SIA is predominantly caused by nitrate (the 204 Netherlands and Belgium) and sulphate (Germany), while the change for ammo205 nium is modest. Levels of nitrate and sulphate are usually higher in urban or 206 industrial areas in Europe $[14,15]$. In marine and coastal atmospheres, nitric acid 207 is converted into particulate nitrate $\left(\mathrm{NaNO}_{3}\right)$ through the reaction with sea-salt 208 particles resulting in the release of $\mathrm{HCl}: \mathrm{NaCl}+\mathrm{HNO} 3 \rightarrow \mathrm{NaNO} 3+\mathrm{HCl}$. In 209 contrast to $\mathrm{NH}_{4} \mathrm{NO}_{3}, \mathrm{NaNO}_{3}$ is a non-volatile compound under atmospheric 210 conditions; therefore, partitioning of nitric acid into the sea salt is irreversible. 211 A similar reaction applies for sulphuric acid (and sulphate). Most of the nitrate here 212 is found in the fine mode as ammonium nitrate (and ammonium sulphate).

\section{Anthropogenic and Natural Contributions to PM in North-Western Europe}

215 Important for air pollution policy in Europe is the contribution to PM10 that is of 216 anthropogenic origin. It is this fraction that can be targeted by national and 217 European abatement strategies. Below, a first-order rather pragmatic assessment 
is given of the natural versus anthropogenic contributions to PM in north-western 218 Europe. It is based on the prevalence of major constituents in the chemical mass 219 closure while incorporating specifics of the region considered.

Sea spray emissions are the most important natural source of primary sulphate. 221 Applying the sodium-to-sulphate ratio in seawater learns that roughly 5\% of the 222 particulate sulphate is of marine origin. Though sulphate may be emitted directly into 223 the atmosphere [17], its major source is the oxidation of sulphur dioxide. In north- 224 western Europe, anthropogenic $\mathrm{SO}_{2}$ emissions are derived mostly from the combus- 225 tion of sulphur-containing fuels for power generation and international shipping. In 226 Europe, natural emissions for $\mathrm{SO}_{2}$ include volcanoes, but given location, height and 227 distance to the Netherlands, their contribution is probably low (i.e. not more than $1 \% 228$ to ground level sulphate). Contributions of other biogenic sources of $\mathrm{SO}_{2}$ like 229 oxidation of DMS, COS and $\mathrm{H}_{2} \mathrm{~S}$ are also of minor importance [16]. Wildfire 230 emissions of $\mathrm{SO}_{2}$ are commonly neglected in studies directed to wild land fire 231 emissions. In the approximation here $5 \%$ is used as a conservative estimate. To 232 estimate how much of the nitrate is natural, emissions from soil, biomass burning and 233 lightning should be considered. Studies on NO emissions from soil report emissions 234 between 59 and $190 \mathrm{kton}$ in the EU15 ([17, 30]). Relative to the total inventoried 235 emissions, the central value is $4 \%$. From these emissions, about two-third is attributed 236 to agricultural soils and one-third to forest soils. Soil $\mathrm{NO}_{\mathrm{x}}$ emissions largely depend 237 on the nutrient input (through fertilisation or atmospheric deposition) implying that 238 the abovementioned contribution is only partly natural. Lightning depends linearly on 239 the amount of convective precipitation. In Europe, corresponding emissions are 240 estimated to be about $1 \%$ (65 kton) of the total inventoried emissions. It mainly 241 takes place between 1 and $5 \mathrm{~km}$ altitude and mostly in southern Europe (Friedrich 242 et al. 2008). Wild fires estimates range between 20 and $50 \mathrm{kton}$ (Friedrich et al. 2008; 243 [18]) and occur mostly in countries around the Mediterranean. Given the short life 244 time of NOx and the rather short transport distance of nitrate, we assume that 245 lightning and wild land fires can be neglected as sources in north-western Europe. 246 In the approximation here, the natural fraction of $\mathrm{NO}_{\mathrm{x}}$ emissions and therewith nitrate 247 is taken between $0 \%$ and $5 \%$.

Ammonium in aerosols originates from the neutralisation of sulphuric and nitric 249 acid by ammonia. Ammonia is emitted by different sources, most notably animal 250 manure, traffic and application of fertiliser. In general, emissions are for the largest 251 part (80-95\%) associated with agricultural activities [19]. Erisman et al. [20] 252 estimated the natural emissions at about $10 \%$ of the total emissions in Europe. This 253 percentage includes contributions from wild animals and wetlands. We assume a 254 similar percentage for ammonium in north-western Europe.

The main source of elemental carbon is the (incomplete) combustion of fossil 256 fuels. Wild land fires are occasional sources of vast amounts of carbonaceous 257 particles. Though wild land fires may seem natural, the vast majority of present- 258 day fires are due to human behaviour. Hence, elemental carbon is almost exclu- 259 sively anthropogenic.

Organic matter contains numerous chemical constituents of which only a small 261 fraction has been identified. Organic carbon is released by the incomplete combus- 262 tion of fuels but in addition originates from farming activities (stables, harvesting) 263 
as well as from nature. Anthropogenic combustion sources as well as (small) stable emissions have been inventoried. Half of the observed concentrations of OC $[21,22]$ can be explained. Hence, a significant (unknown) contribution is from anthropogenic sources like secondary formation, wildfires, harvesting, abrasion processes and biological material (fungal spores and plant debris). As mentioned previously, ${ }^{14} \mathrm{C}$ analysis suggests that some $70 \%$ of the OC mass in the Netherlands is of living material where biogenic SOA, agriculture and other landscaping activities may have contributed. The complicating factor in the estimation of the natural part of $\mathrm{OM}$ is the uncertainty related to its secondary component (oxidation of VOCs yields products with low vapour pressures that may condense on existing aerosol) as the major formation routes are not well known. As a consequence, the ratio of natural to anthropogenic SOA is under debate. It is postulated that biogenic sources are a major contributor to atmospheric SOA (e.g. [22]). Assuming that the unexplained OC using present-day emission inventories is for the largest part SOA, an upper limit of around 50\% for natural OM is obtained. As a substantial part of the SOA may very well be anthropogenic, it is postulated that half of the SOA as natural, leading to a lower limit of $25 \%$ for natural OM.

Sources of mineral dust in total PM10 are wind erosion of bare soils, agricultural land management, resuspension of road dust from paved an unpaved roads, road wear, handling of materials and building and construction activities. Only wind erosion may contribute to the natural fraction. Saharan dust is regularly transported to countries around the Mediterranean Sea. In north-western Europe, dust transport from the Sahara occurs once or twice a year and is therefore not very significant. Korcz et al. [23] and Schaap et al. [24] show that windblown dust at the European continent is a rather small source compared to traffic resuspension and agricultural land management. More importantly, the windblown dust source strength from soils other than arable land is low. Windblown dust emissions are strongly related to anthropogenic changes in surface vegetation cover and are regarded as mostly anthropogenic. Consequently, the total mineral dust concentration in air is expected to be anthropogenic for a large part. In the approximation, $10 \%$ is assumed as a conservative estimate for the natural contribution to MD.

The emission of sea salt is mainly dependent on wind speed. It is considered the second largest contributor in the global aerosol budget, as a vast area of the earth consists of sea. The aerosols consist mainly of sodium chloride. Other constituents of atmospheric sea salt reflect the composition of sea water (magnesium, sulphate, calcium and potassium). Sea salt is the only pure natural aerosol component.

The anthropogenic contribution of the unknown part is by definition unknown. Water accounts to some extent for the unknown fraction. As most of that water may be associated with SIA, it is likely that a significant part of the unknown fraction is anthropogenic. It is assumed that the anthropogenic and natural parts of the unknown fraction resemble those of the defined mass.

The natural fraction in the total mass can now be obtained by adding the relative natural mass contributions per constituent. For instance, $10 \%$ of PM10 is associated with sea salt adding to $10 \%$ of natural PM10 (see Table 2). Note that this fraction 8 represents the source attribution and therewith fresh sea salt as discussed in the 
Anthropogenic and Natural Constituents in PM10 at Urban and Rural Sites in...

Table 2 Analysis of the natural contribution (\%), for all components, and for PM10 as a whole, at the rural background site (Hellendoorn)

\begin{tabular}{llll}
\hline Composition & PM10 (\%) & Natural contribution (\%) & Rural background PM10 (\%) \\
\hline $\mathrm{NO}_{3}$ & 20 & $0-5$ & $0-1$ \\
$\mathrm{SO}_{4}$ & 14 & 5 & 1 \\
$\mathrm{NH}_{4}$ & 8 & 10 & 1 \\
$\mathrm{MD}$ & 10 & 20 & 2 \\
$\mathrm{SS}$ & 10 & 100 & 10 \\
$\mathrm{EC}$ & 6 & 0 & 0 \\
$\mathrm{OM}$ & 15 & $25-50$ & $4-8$ \\
$\mathrm{Sum}$ known & & $18-23$ \\
Unknown & 15 & $3-3$ \\
Total & \\
For each constituent, the relative contributions to PM10 are listed as well as the estimated natural \\
contributions. The last column provides the resulting natural contribution, expressed in a percent- \\
age of PM10 mass (with a low-high estimate for the natural contribution in $\mathrm{NO}_{3}$ and OC) \\
a The natural contribution is assumed to be the same as the total natural percentage of PM mass \\
without the unknown fraction
\end{tabular}

previous section and would be lower when one reflects the chloride loss in this 309 calculation. Nitrate contributes $20 \%$, of which $0-5 \%$ is assumed to be natural 310 resulting in a contribution of $0-1 \%$ natural PM10 for the low and high case, 311 respectively. Hence, nitrate contributes very little to the natural fraction. Adding 312 all contributions, the estimated natural fraction of PM10 is between $21 \%$ and $26 \% .313$ Hence, between one-fifth and one-quarter of PM10 is estimated to be of natural 314 origin. The uncertainty in such a simple analysis is quite large. Hence, we rounded 315 all data to the closest interval of a half per cent. As such, the uncertainty in the 316 summation is around 2-3\%. It is concluded that the most important natural 317 contributions originate from sea salt $(100 \%)$ and organic material (with an upper 318 limit of 50\%).

\section{Modelled Origin of Particulate Matter in the Netherlands and Spain}

So far, we have used composition measurements and mass closure studies to 322 interpret PM distributions and origin. Furthermore, a simple analysis on the natural 323 fraction of PM was described. Detailed speciation data sets such as used in this 324 study enable to use more elaborate statistical approaches to identify source origins, 325 such as positive matrix factorisation [25]. Examples of these techniques are given 326 for Germany elsewhere in this book (Quass et al. 2012). However, these methods 327 AU1] are only able to distinguish between a limited number of source categories. 328 Furthermore, they are typically not able to provide a source apportionment for 329 secondary components. 
Complementary to experimental data, a chemical transport model (CTM) can be 332 used to obtain a more detailed source apportionment. CTMs provide calculations of 333 the evolution of the air pollution situation across a region based on emission 334 inventories and atmospheric process descriptions. Here we use the LOTOS335 EUROS CTM to investigate the origin of particulate matter in north-western 336 Europe. The LOTOS-EUROS model has been equipped with a module that tracks 337 the contribution of different source sectors throughout a model simulation [26].

338 Hence, for each modelled process, e.g. advection and chemistry, the concentration 339 change is calculated as well as change in source contributions. The module has been 340 used to assess the origin of PM in the Netherlands by Hendriks et al. [27]. Here, we 341 summarise the results for the Netherlands assuming it to be representative for north342 western Europe (i.e. Belgium and western Germany) and also provide results for 343 Spain to contrast the two regions.

344 To assess the source contributions to modelled PM10, two simulations were 345 performed. A simulation across Europe at $0.5^{\circ}$ longitude $\times 0.25^{\circ}$ latitude (about $34628 \times 28 \mathrm{~km}$ ) resolution provided the results which were used as boundary 347 conditions for a simulation at a resolution of $0.125^{\circ}$ longitude $\times 0.0625^{\circ}$ latitude $348(7 \times 7 \mathrm{~km})$ centred over the Netherlands. The simulations were performed for 3492007,2008 and 2009 to average out meteorological variability. Labels were applied 350 to distinguish Dutch and foreign emissions sources specified to SNAP (Selected 351 Nomenclature for sources of Air Pollution) level 1, which uses ten main sectors:

352 1. Power generation: combustion in energy and transformation industries

353 2. Other combustion: nonindustrial combustion mainly households

354 3. Industrial combustion in manufacturing industry

355 4. Industrial process emissions

356 5. Extraction and distribution of fossil fuels and geothermal energy

357 6. Solvent use

358 7. Road transport

359 8. Other transport: other mobile sources and machinery

360 9. Waste treatment and disposal

361 10. Agriculture

362 Natural emissions and PM originating from the initial conditions, aloft 363 conditions and PM coming from regions outside the model domain were tracked 364 as well.

365 In Fig. 4, the modelled PM10 distribution is shown for Europe. For the 366 Netherlands, modelled PM10 concentrations range from $13 \mu \mathrm{g} / \mathrm{m}^{3}$ in the North 367 and $18 \mu \mathrm{g} / \mathrm{m}^{3}$ in the South to $22 \mu \mathrm{g} / \mathrm{m}^{3}$ in the densely populated and industrialised 368 western part of the country. Comparison to observations shows that present-day 369 chemistry transport models are not able to fully explain the observed particulate 370 matter mass. LOTOS-EUROS misses about $40 \%$ of the measured PM10 mass, of 371 which a large part can be explained. The model underestimates nitrate concen372 trations by about $25 \%$, whereas total carbon concentrations are underestimated by 373 about $60 \%$. The latter is largely attributed to organic matter and corresponds to up 374 to $4-5 \mu \mathrm{g} / \mathrm{m}^{3}$ of $\mathrm{OM}$. The reason for the underestimation of organic carbon is that 

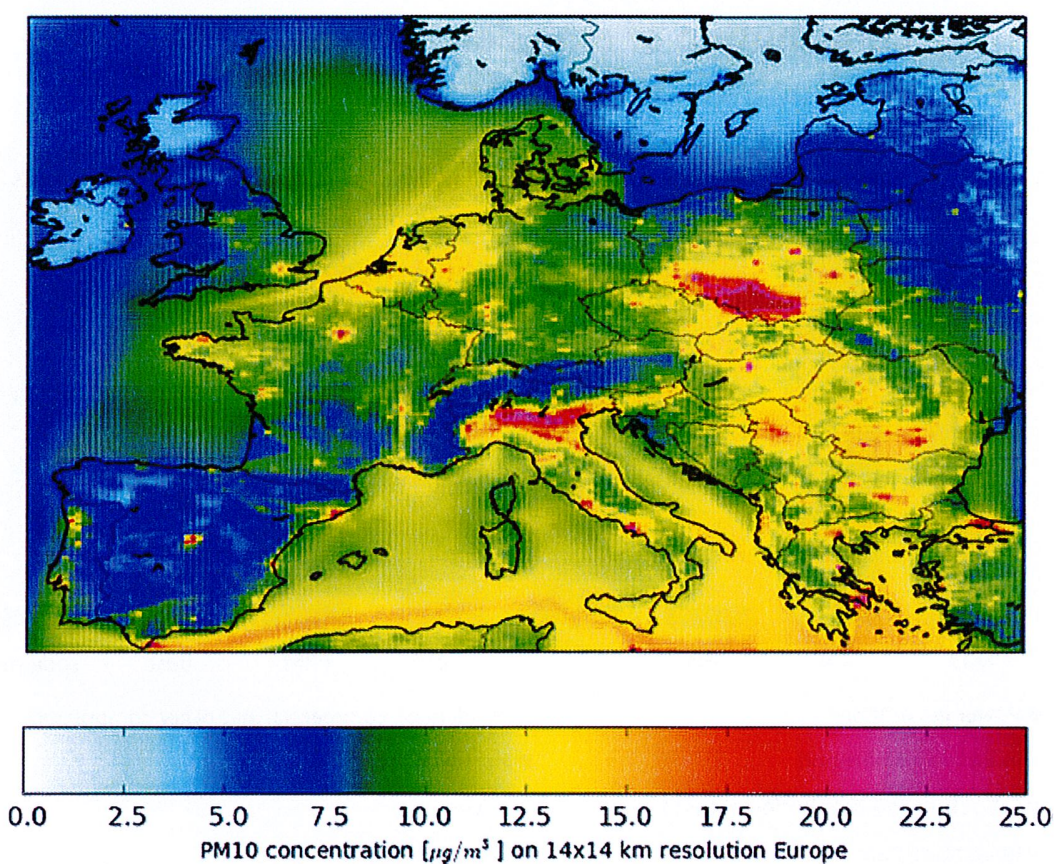

Fig. 4 Modelled distribution of PM10 across Europe for 2007-2009 excluding mineral dust

the model does not include a relevant process description. The uncertainties in the 375 process description including secondary organic aerosol formation and the semi- 376 volatile nature of $\mathrm{OM}$ are so large that they are not considered robust enough to 377 incorporate in a source apportionment study. Model to observation comparison 378 shows no significant biases for sulphate, ammonium and sea salt. Hence, the source 379 apportionment presented here covers about $60 \%$ of the observed PM mass. $\quad 380$

The source apportionment is performed for each component separately. Figure 5381 shows the source attribution per sector for the most important PM components 382 averaged across the Netherlands. Some components are dominated by a few sectors. 383 Agriculture is by far the most important source of ammonium, causing over $90 \%$ of 384 the emissions and concentration of this substance in the Netherlands. The mineral 385 dust concentration in the Netherlands originates for about $25 \%$ from outside the 386 model domain which is mainly associated with a few desert dust episodes. The 387 remaining mineral dust is equally divided between agriculture and road transport. 388 The unspecified primary particulate mass is dominated by industrial process 389 emissions. Nitrate, sulphate and EC concentrations originate mainly from sectors 390 in which fuel combustion is important (e.g. transport, industrial combustion and 391 power generation). For the other components, the sector origin is more diffuse. $\quad 392$

Summing all separate contributions allows to assess the origin of the modelled 393 total mass. The most important contributions to total PM10 mass in this region are 394 associated with agriculture, on-road and off-road transport and natural sources. 395 Together these explain about $75 \%$ of the modelled mass. Secondary contributions 396 


\section{Contribution of emission sources to PM components}

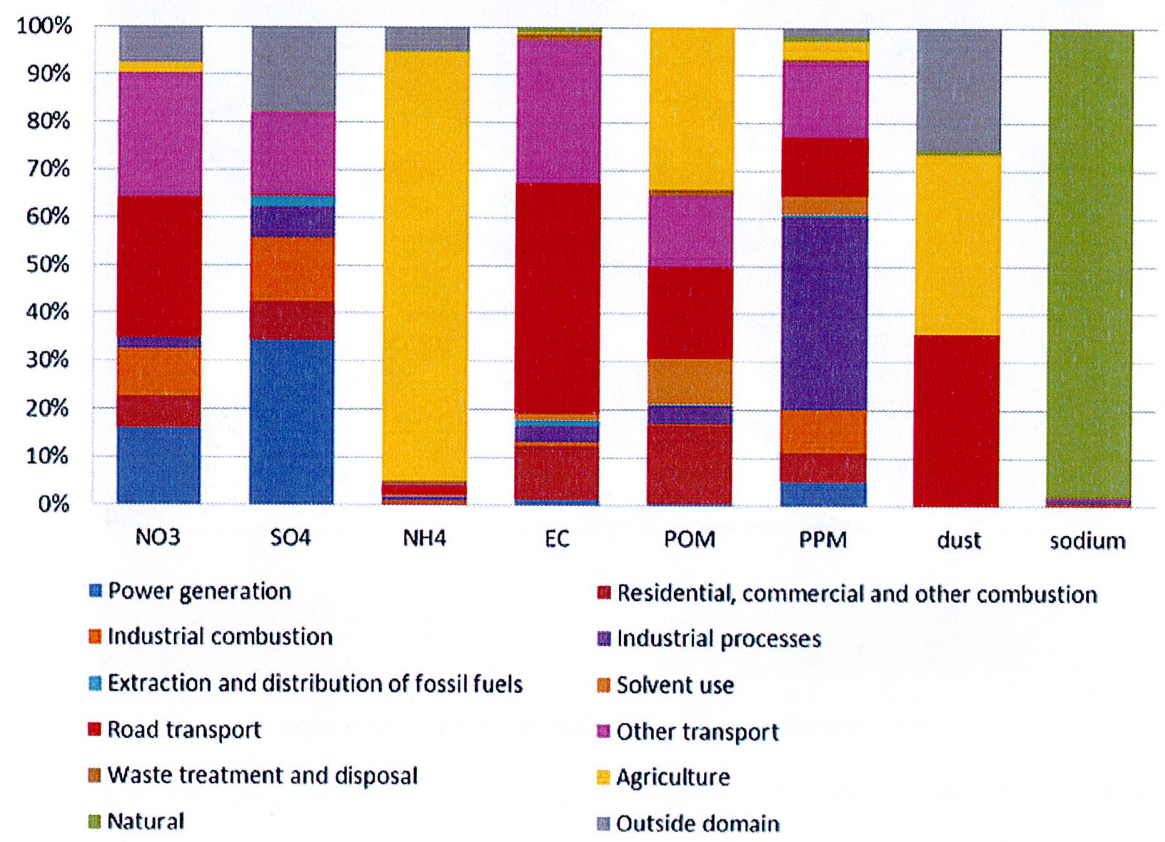

Fig. 5 Annual average origin of modelled PM10 components in the Netherlands [27]

397 are derived from power generation, industrial processes and combustion as well as 398 households. Waste treatment, solvent use and extraction of fossil fuels do not 399 contribute significantly. Of the modelled part, $70-80 \%$ of PM10 over the 400 Netherlands is anthropogenic, which is in agreement with the analysis described 401 in the previous section.

402 To investigate the differences in source contributions between peak episodes and 403 periods with lower modelled PM concentrations, all days were categorised based on 404 the average modelled concentration of PM10. The source attribution as function of 405 PM10 concentration in the Netherlands is shown in Fig. 6. The natural contribution 406 is highest when the total modelled PM concentration is low. Low concentrations are 407 associated with westerly winds, resulting in transport of sea salt from the North Sea 408 and Atlantic Ocean to the Netherlands. High PM concentrations occur mainly with 409 easterly winds and/or stable stagnant conditions, during which the influx of sea salt 410 is much smaller. The increase in concentration going from low to high PM levels is 411 proportional for most sectors, except for agriculture and transport, which become 412 more important mainly due to the more than proportional rise in ammonium nitrate 413 concentrations. In the high concentration range also the impact of a few desert dust 414 episodes is visible. 


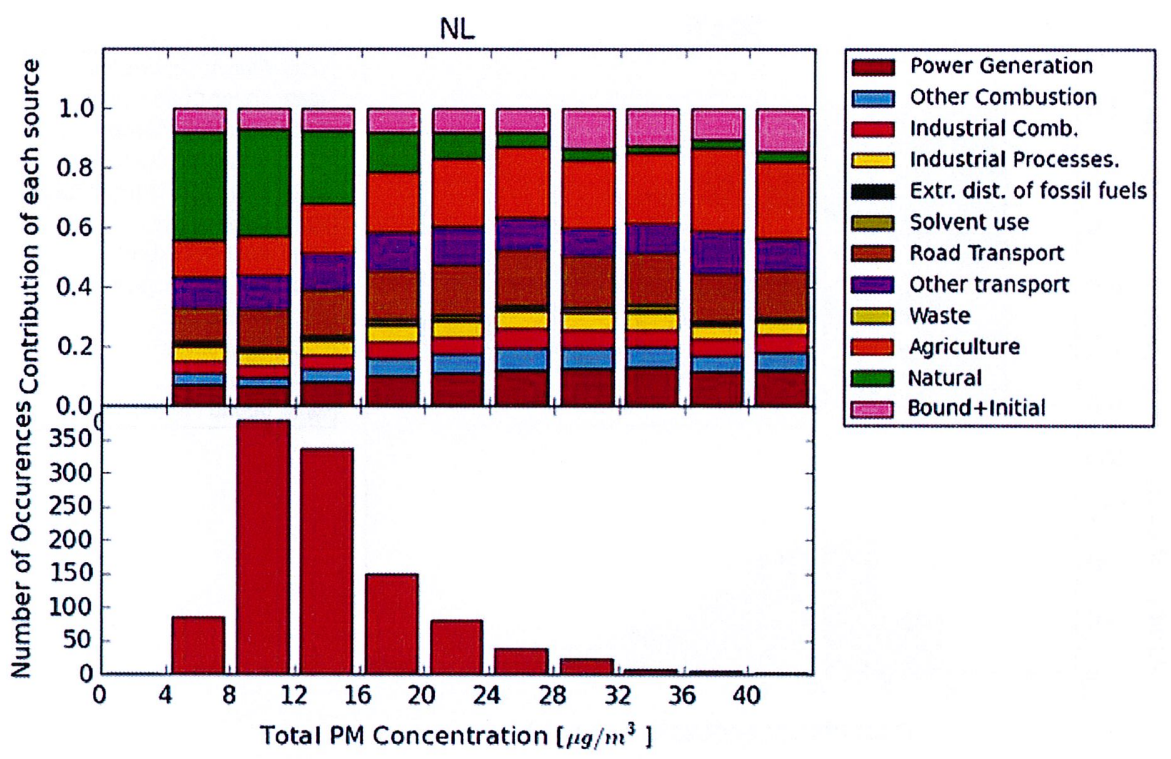

Fig. 6 Modelled source attribution on a sectorial basis for the Netherlands as function of total modelled PM10 mass. For each concentration bin, the number of occurrences is given

To contrast the situation in north-western Europe, we also present results for 415 Spain. Before addressing the source attribution, we need to highlight an important 416 difference between the two regions. In north-western Europe, the population 417 density is generally high, and cities are located close to each other. In Spain, this 418 is not the case. Major cities with high PM10 concentrations are located far from 419 each other, and away from the coast population density is very low. Hence, large 420 differences in concentrations are present between the rural background and urban 421 concentration levels.

Figure 7 presents the source attribution as function of modelled PM10 concentra- 423 tion averaged across the whole Spanish mainland. Hence, the apportionment is 424 dominated by the rural areas. This feature also explains the relatively low modelled 425 concentrations, also in comparison to north-western Europe. Note that the emissions 426 from the ocean are depicted as natural, whereas those of dust are classified as 427 boundary. This is due to the fact that a global model simulation incorporating desert 428 dust is used to provide the influx at the model domain boundaries. Whereas sea-salt 429 concentration decreases with PM in Spain, the impact of desert dust on PM episodes 430 is clearly recognisable and, for obvious reasons (Saharan desert sand), much larger 431 than in north-western Europe. Summarised, the natural sources (sea salt and desert 432 dust) contribute about half of the modelled PM10 concentrations across the whole of 433 Spain. Anthropogenic sources that contribute significantly are similar to those in 434 north-western Europe and comprise agriculture, transport and industrial combustion. 435 Zooming into large urban agglomerations such as Madrid and Barcelona, the impor- 436 tance of anthropogenic sources is significantly larger than for the country as a whole 437 and cause regional maxima modelled PM10 (Fig. 4). It is especially the transport 438 sector that significantly gains importance. 


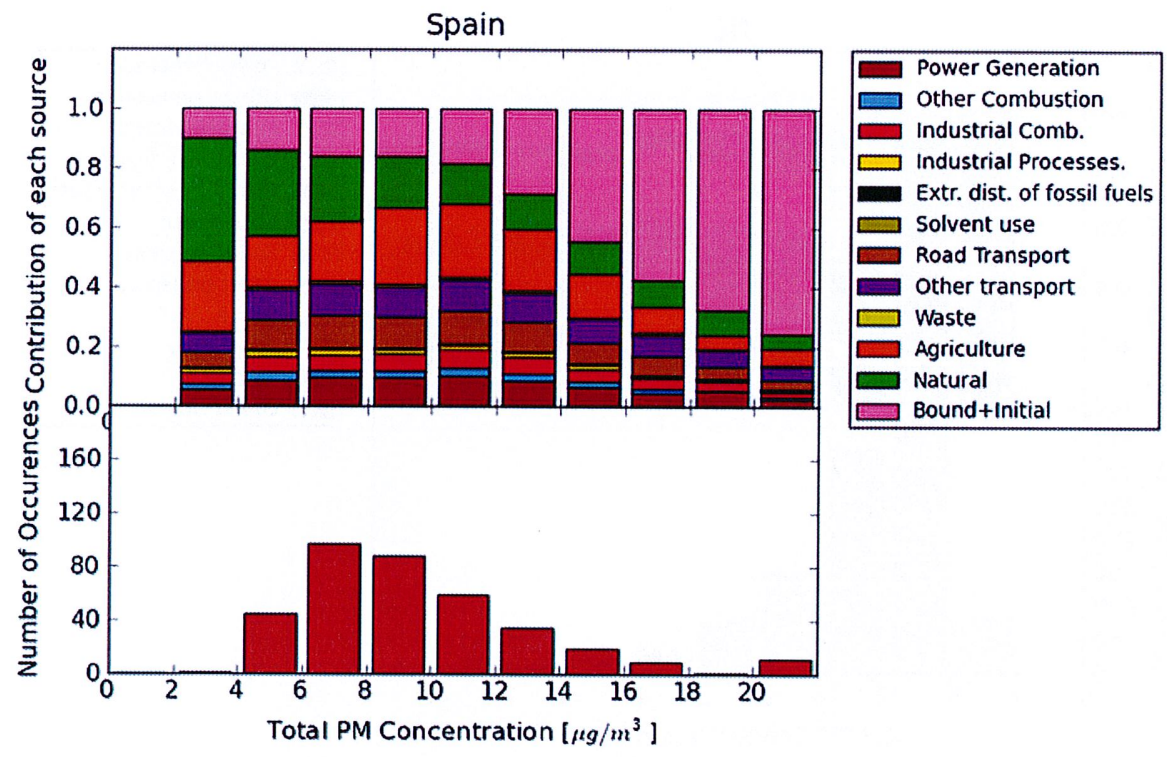

Fig. 7 Modelled source attribution on a sectorial basis for the Spain as function of total modelled PM10 mass. For each concentration bin, the number of occurrences is given. Note that desert dust is incorporated as boundary conditions in the simulations, explaining the large contribution of boundary conditions for Spain

\section{Concluding Remarks}

441 The chemical composition of PM10 on various measurement sites in the 442 Netherlands, Germany and Belgium shows a considerable conformity. Always, 443 SIA is the major constituent $( \pm 40 \%)$ followed by the carbonaceous compounds $444( \pm 25 \%)$. Contributions of sea salt and mineral dust vary between $10 \%$ and $15 \%$ 445 depending on location (distance to the North Sea) or presence of local sources. The 446 unidentified mass is only in the order of $15 \%$ showing that the composition of PM10 447 in the region is rather well known.

448 PM10 concentrations are systematically higher at urban sites. Roughly, every 449 constituent in PM10 appears higher in the urban area. The reduced dispersion in 450 urban areas and the presence of dominating (anthropogenic) sources are the main 451 reasons. However, the locations and distance between the rural and urban site may 452 also have influenced the analysis. For instance, the higher urban concentrations of 453 sea salt are induced by a closer proximity to the coast, though a small gradient in 454 salt may be explained by the resuspension of road salt in winter. Elementary carbon 455 in cities primarily originates from diesel emissions. The organic mass is a very 456 complex group with anthropogenic and natural sources. Although Robinson et al. 457 [28] showed that photo-oxidation of diesel emissions rapidly generates organic 458 aerosol ten Brink et al. [13], indicated that only one-third of the OC in a Dutch city 459 was due to fossil fuel combustion. Hence, the origin of OM remains unclear. 
Mineral dust sources in urban areas include road dust resuspension and demolition 460 and construction activities. There is no apparent reason why the unknown part 461 should also be higher or lower at urban or rural sites. A possible cause may be the 462 amount of water attached to SIA which appears increased. Hygroscopic salts on 463 particles, like ammonium nitrate and ammonium sulphate in the fine fraction, and 464 sodium nitrate and sodium sulphate in the coarse fraction attract water erroneously, 465 increasing the PM mass.

The reason why SIA is higher in urban areas is less obvious as these are 467 secondary aerosols. The observed increment is predominantly caused by more 468 nitrate and sulphate. The reaction of nitric acid and sulphuric acid with the sea- 469 salt aerosol in a marine urbanised environment follows an irreversible reaction 470 scheme. In essence, the chloride depletion stabilises part of the nitrate and sulphate 471 in the coarse mode and may partly explain part of the observed increment. How- 472 ever, it also raises the question how to assign the coarse mode nitrate in the mass 473 closure. The sea salt and nitrate contributions cannot simply be added any more as 474 nitrate replaces chloride. Reduction of $\mathrm{NO}_{\mathrm{x}}$ emissions may cause a reduction of 475 coarse mode nitrate, which is partly compensated by the fact that chloride is not lost 476 anymore. A reduction would yield a net result of $\left(\left(\mathrm{NO}_{3}-\mathrm{Cl}\right) / \mathrm{NO}_{3}=(62-35) / 62=\right) 477$ $27 / 62$ times the nitrate reduction (where the numbers are molar weights of the 478 respective components), and this factor could be used to scale back the coarse 479 nitrate fraction in the chemical mass balance. A similar reasoning may be valid for 480 the anthropogenic sulphate in the coarse fraction. Corrections like these are uncom- 481 mon in current mass closure studies, and consequences will have to be explored in 482 more detail.

Important for the national and European air pollution policy is the question how 484 much of the measured particulate matter is of anthropogenic origin. It is this 485 fraction that can be targeted by national and European abatement strategies. A 486 pragmatic assessment of the natural versus anthropogenic contributions to PM was 487 given here. The estimation is that between $20 \%$ and $25 \%$ of PM10 is of natural 488 origin for countries like Germany, Belgium and the Netherlands. Hence, the 489 majority of PM in the north-western European region is of anthropogenic origin. 490 The uncertainty in such an analysis is considerable, and the result should be taken as 491 indicative.

A CTM was used to obtain a more detailed source apportionment for the 493 Netherlands. The model explains about $60 \%$ of the observed PM10 mass concen- 494 tration. Application of a dedicated source apportionment module showed that the 495 origin of the individual species may differ considerably. The most important 496 contributions to total PM10 mass in north-western Europe are associated with 497 agriculture, on-road and off-road transport as well as natural sources (sea salt). 498 Together these explain about $75 \%$ of the modelled mass. Secondary contributions 499 are derived from power generation, industrial processes and combustion as well as 500 households. Of the modelled part, $70-80 \%$ of PM10 over the Netherlands is 501 anthropogenic. The increase in source contribution going from low to high PM 502 levels is proportional for most sectors, except for agriculture and transport, which 503 become more important mainly due to the more than proportional rise in ammo- 504 nium nitrate concentrations. Sea-salt concentrations decline with rising PM10. 505 
512 Acknowledgements The use of the "CHEMKAR" data in this study was kindly permitted by the 513 Flemish Environmental Agency [8]. The "BOP" campaign was organised by a consortium of the 514 Dutch research institutes (ECN, TNO and RIVM) within the framework of the second Netherlands 515 Research Programme on Particulate Matter (sponsored by the Ministry of Infrastructure and 516 Environment I\&M). The German air quality campaign (executed by IUTA) was sponsored by 517 the North Rhine-Westphalia State Agency for Nature, Environment and Consumer Protection 518 (LANUV) and the North Rhine-Westphalia Ministry of Environment (MKULNV). The LOTOS519 EUROS modelling exercise presented here was partly funded by the 7th Framework Programme of 520 the European Commission EnerGEO and by the second Netherlands Research Programme on 521 Particulate Matter.

\section{References} 44:1308-1320 Environ 41:1-17

1. EEA (2007) Air pollution in Europe 1990-2004, EEA report 2/2007, Copenhagen

2. Putaud J-P, Raesa F, Van Dingenen R, Bruggemann E, Facchini M, Decesari S, Fuzzi S, Gehrig R, Hueglin C, Laj P, Lorbeer G, Maenhaut W, Mihalopoulos N, Mueller K, Querol X, Rodriguez S, Schneider J, Spindler G, ten Brink H, Torseth K, Wiedensohler A (2004) A European aerosol phenomenology - 2: chemical characteristics of particulate matter at kerbside, urban, rural and background locations in Europe. Atmos Environ 38:2579-2595

3. Putaud J-P, Van Dingenen R, Alastuey A, Bauer H, Birmili W, Cyrys J, Flentje H, Fuzzi S, Gehrig R, Hansson HC, Harrison RM, Herrmann H, Hitzenberger R, Hüglin C, Jones AM, Kasper-Giebl A, Kiss G, Kousa A, Kuhlbusch TAJ, Löschau G, Maenhaut W, Molnar A, Moreno T, Pekkanen J, Perrino C, Pitz M, Puxbaum H, Querol X, Rodriguez S, Salma I, Schwarz J, Smolik J, Schneider J, Spindler G, ten Brink H, Tursic JJ, Viana M, Wiedensohler A, Raes F (2009) A European aerosol phenomenology - 3: physical and chemical characteristics of particulate matter from 60 rural, urban, and kerbside sites across Europe. Atmos Environ

4. Viana M, Kuhlbusch TAJ, Querol X, Alastuey A, Harrison RM, Hopke PK, Winiwarter W, Vallius M, Szidat S, Prévôt ASH, Hueglin C, Bloemen H, Wåhlin P, Vecchi R, Miranda AI, Kasper-Giebl A, Maenhaut W, Hitzenberger R (2008) Source apportionment of particulate matter in Europe: a review of methods and results. J Aerosol Sci 39:827-849

5. Sillanpää M, Hillama R, Saarikoski S, Frey A, Pennanen A, Makkonen U, Spolnik Z, Van Grieken R, Braniš M, Brunekreef B, Chalbot M-C, Kuhlbusch T, Sunyer J, Kerminen V-M, Kulmala M, Salonen RO (2006) Chemical composition and mass closure of particulate matter at six urban sites in Europe. Atmos Environ 40:212-223

6. Salvador P, Artı B, Querol X, Alastuey A, Costoya M (2007) Characterisation of local and external contributions of atmospheric particulate matter at a background coastal site. Atmos

7. Mazzei F, D'Alessandro A, Lucarelli F, Nava S, Prati P, Valli G, Vecchi R (2008) Characterization of particulate matter sources in an urban environment. Sci Total Environ 41:81-89 
Anthropogenic and Natural Constituents in PM10 at Urban and Rural Sites in...

8. VMM (2009): Chemkar PM10: Chemische karakterisatie van fijn stof in Vlaanderen, 550 2006-2007. http://www.vmm.be/publicaties/2009/CK_PM10_TW.pdf/view (in Dutch with 551 English summary)

9. PBL, Resultaten op hoofdlijnen en beleidsconsequenties, Beleidsgericht Onderzoek- 553 sprogramma Fijn Stof, PBL-rapport 500099013, 2010

10. Querol X, Alastuey A, Rodriguez S, Plana F, Ruiz CR, Cots N, Massague G, Puig O (2001) 555 PM10 and PM2.5 source apportionment in the Barcelona Metropolitan Area, Catalonia, Spain. 556 Atmos Environ 35(36):6407-6419

11. Denier van der Gon H, Jozwicka M, Hendriks E, Gondwe M, Schaap M (2010) Mineral dust as 558 a constituent of particulate matter. PBL report 500099003, Bilthoven, the Netherlands 559

12. Weijers EP, Sahan E, Ten Brink HM, Schaap M, Matthijsen J, Otjes RP, Van Arkel F (2010) 560 Contribution of secondary inorganic aerosols to PM10 and PM2.5 in the Netherlands; 561 measurements and modelling results. PBL Report 500099006, Bilthoven, the Netherlands 562

13. ten Brink HM, Weijers E.P, Röckmann T, Dusek U (2010) ${ }^{14} \mathrm{C}$ analysis of filter samples for 563 source apportionment of PM in the Netherlands, ECN Report E-10-005, 2010

14. Perez N, Castillo S, Pey J, Alastuey A, Viana M, Querol X (2008) Interpretation of the 565 variability of regional background aerosols in the Western Mediterranean. Sci Total Environ 566 407:527-540

15. Drechsler S, Uhrner U, Lumpp R (2006) Sensitivity of urban and rural ammonium nitrate 568 particulate matter to precursor emissions in Southern Germany. Workshop on Contribution of 569 Natural Sources to PM Levels in Europe, JRC Ispra, 12-13 October 2006

16. Bates TS, Lamb BK, Guenther A, Dignon J, Stoiber RE (1992) Sulfur emissions to the 571 atmosphere from natural sources. J Atmos Chem 14:315-337 572

17. Simpson D, Winiwarter W, Börjesson G, Cinderby S, Ferreiro A, Guenther A, Hewitt N, 573 Janson R, Khalil MAK, Owen S, Pierce T, Puxbaum H, Shearer M, Skiba U, Steinbrecher R, 574 Tarrason L, Öquist MG (1999) Inventorying emissions from nature in Europe. J Geophys Res 575 104:8113-8152

18. Hoelzemann J, Schultz MG, Brasseur GP, Granier C, Simon M (2004) Global wildland fire 577 emission model (GWEM): evaluating the use of global area burnt satellite data. J Geophys Res 578 109:D14S04

19. van der Hoek KW (1998) Estimating ammonia emission factors in Europe: summary of the 580 work of the UNECE ammonia expert panel. Atmos Environ 32:315-316 581

20. Erisman JW, Sutton MA, Galloway J, Klimont Z, Winiwarter W (2009) How a century of 582 ammonia synthesis changed the world. Nat Geosci 1:636-639 583

21. Schaap M, Spindler G, Schulz M, Acker K, Maenhaut W, Berner A, Wieprecht W, Streit N, 584 Mueller K, Brüggemann E, Putaud J-P, Puxbaum H, Baltensperger U, ten Brink HM (2004) 585 Artefacts in the sampling of nitrate studied in the "INTERCOMP" campaigns of EUROTRAC- 586 AEROSOL. Atmos Environ 38:6487-6496 587

22. Simpson D, Yttri KE, Klimont Z, Kupiainen K, Caseiro A, Gelencsér A, Pio CA, Puxbaum H, 588 Legrand M (2007) Modeling carbonaceous aerosol over Europe: analysis of the CARBOSOL 589 and EMEP EC/OC campaigns. J Geophys Res Atmos 112:D23S14 590

23. Korcz M, Fudała J, Kliś C (2009) Estimation of windblown dust emissions in Europe and its 591 vicinity. Atmos Environ 43:1410-1420 592

24. Schaap M, Manders AMM, Hendriks ECJ, Cnossen JM, Segers AJS, Denier van der Gon HAC, 593 Jozwicka M, Sauter FJ, Velders GJM, Matthijsen J, Builtjes PJH (2009) Regional modelling of 594 particulate matter for the Netherlands, PBL Report 500099006, Bilthoven, the Netherlands 595

25. Kuhlbusch TAJ, John AC, Quass U (2010) Sources and source contributions to fine particles. 596 Biomarkers 14:23-28

26. Schaap M, Kranenburg R, Huibregtse JN, Segers AJA, Hendriks C (2012) Development of 598 a source apportionment module in LOTOS-EUROS. TNO report TNO-060-UT-2012- 599 00161,2012

27. Hendriks C, Kranenburg R, Kuenen J, van Gijlswijk R, Denier van der Gon H, Schaap M 601 (2012) The origin of ambient Particulate Matter concentrations in the Netherlands, TNO report 602 060-UT-2012-00474, Utrecht, the Netherlands 
28. Robinson AL, Donahue NM, Shrivastava MK, Weitkamp EA, Sage AM, Grieshop AP, Lane TE, Pierce JR, Pandis SN (2007) Rethinking organic aerosols: semi volatile emissions and photochemical aging. Science 315:1259-1262

29. Almeida SM, Pio CA, Freitas MC, Reis MA, Trancoso MA (2005) Source apportionment of fine and coarse particulate matter in a sub-urban area at the Western European Coast. Atmos Environ 39:3127-3138

30. Friedrich R (2007) Improving and applying methods for the calculation of natural and biogenic emissions and assessment of impacts to the air quality. Final project activity report 2007. http://natair.ier.uni-stuttgart.de/. Accessed March 2011

31. Weijers EP, Schaap M, Nguyen L, Matthijsen J, Denier van der Gon HAC, ten Brink HM, Hoogerbrugge R (2011) Anthropogenic and natural constituents in particulate matter in the Netherlands. Atmos Chem Phys 11:1-14

32. Weijers EP, Sahan E, Brink HM, ten Schaap M, Matthijsen J, Otjes RP, van Arkel F (2012) Contribution of secondary inorganic aerosols to PM10 and PM2.5 in the Netherlands; measurement and modeling results. PBL report 500099006, Bilthoven

33. Shtepa BG, Kudrin BA, Zonn IS, Orlova VP, Volynov AM (1975) Land reclamation in the USSR. Kolos, Moscow, 271 pp 


\section{Author Queries}

Chapter No.: 207

\begin{tabular}{|l|l|l|}
\hline Query Refs. & Details Required & Author's response \\
\hline AU1 & Please provide chapter details. & \\
\hline
\end{tabular}

